\title{
Phosphatase of regenerating liver-3 is expressed in acute lymphoblastic leukemia and mediates leukemic cell adhesion, migration and drug resistance
}

\author{
Magnus A. Hjort ${ }^{1,2}$, Pegah Abdollahi ${ }^{1,3}$, Esten N. Vandsemb ${ }^{1,3}$, Mona H. Fenstad ${ }^{1,3}$, \\ Bendik Lund ${ }^{1,2}$, Tobias S. Slørdahl ${ }^{1,4}$, Magne Børset ${ }^{1,3}$ and Torstein B. R ${ }^{1,2}$ \\ ${ }^{1}$ Department of Clinical and Molecular Medicine, Norwegian University of Science and Technology, Trondheim, Norway \\ ${ }^{2}$ Children's Clinic, St. Olavs Hospital, Trondheim University Hospital, Trondheim, Norway \\ ${ }^{3}$ Department of Immunology and Transfusion Medicine, St. Olavs Hospital, Trondheim University Hospital, Trondheim, Norway \\ ${ }^{4}$ Department of Hematology, St. Olavs Hospital, Trondheim University Hospital, Trondheim, Norway \\ Correspondence to: Magnus A. Hjort, email: magnus.a.hjort@ntnu.no \\ Keywords: PRL-3; acute lymphoblastic leukemia; migration; adhesion; drug resistance \\ Received: October 11,2017 Accepted: December 01,2017 Published: December 13, 2017 \\ Copyright: Hjort et al. This is an open-access article distributed under the terms of the Creative Commons Attribution License 3.0 \\ (CC BY 3.0), which permits unrestricted use, distribution, and reproduction in any medium, provided the original author and source \\ are credited.
}

\section{ABSTRACT}

Phosphatase of regenerating liver-3 (PRL-3/PTP4A3) is upregulated in multiple cancers, including BCR-ABL1- and ETV6-RUNX-positive acute lymphoblastic leukemia (ALL). With this study, we aim to characterize the biological role of PRL-3 in B cell ALL (B-ALL). Here, we demonstrate that PRL-3 expression at mRNA and protein level was higher in B-ALL cells than in normal cells, as measured by qRT-PCR or flow cytometry. Further, we demonstrate that inhibition of PRL-3 using shRNA or a small molecular inhibitor reduced cell migration towards an SDF-1a gradient in the preB-ALL cell lines Reh and MHH-CALL-4. Knockdown of PRL-3 also reduced cell adhesion towards fibronectin in Reh cells. Mechanistically, PRL-3 mediated SDF-1a stimulated calcium release, and activated focal adhesion kinase (FAK) and Src, important effectors of migration and adhesion. Finally, PRL-3 expression made Reh cells more resistance to cytarabine treatment. In conclusion, the expression level of PRL-3 was higher in B-ALL cells than in normal cells. PRL-3 promoted adhesion, migration and resistance to cytarabine. PRL-3 may represent a novel target in the treatment of B-ALL.

\section{INTRODUCTION}

Acute lymphoblastic leukemia (ALL) is the most common childhood cancer, accounting for approximately one third of pediatric cancers. Major prognostic factors include clinical features at time of diagnosis, and biological and genetic features of leukemic cells [1]. The overall prognosis in children has improved substantially over the last decades, and today the 5-year survival in Western countries has reached $90 \%$. However, ALL is still the most frequent cause of death from cancer in children, mainly due to a poor prognosis at relapse [1]. Thus, identification of novel targets for treatment as well as reduction of treatment-related toxicity are still important for increased survival [2].

Adhesion to bone marrow (BM) stroma and BM niches is vital for both normal and leukemic B-progenitor cells $[3,4]$. Adhesion of $B$ cells to BM stroma is achieved primarily through binding via the beta-1 integrin $\alpha_{4} \beta_{1}$ (very late antigen (VLA)-4) and $\alpha_{5} \beta_{1}$ (VLA-5) [5, 6]. Adhesion enables the cells to receive growth and survival signals, either through integrin-mediated signaling or through stimulation by interleukin (IL)-7 and other cytokines in the bone marrow microenvironment [7]. Integrins are also necessary for the migration of progenitor cells through stromal layers, a process regulated by stromal cell-derived factor-1 alpha (SDF-1a) [8]. During cancer therapy, cell 
adhesion in the BM promotes resistance to chemotherapy $[5,6]$. This cell adhesion-mediated drug resistance (CAMDR) has been considered a cause of minimal residual disease (MRD) and relapse of ALL [6].

PRL-3 is a dual-specificity phosphatase, meaning that it can dephosphorylate both tyrosine and serine/ threonine residues, and is encoded by the gene PTP $4 A 3$. PRL-3 was first described in 1998, and associated with metastatic potential in colorectal cancer [9]. Today, PRL-3 is known to be important for cancer cell motility, adhesion, invasion and metastasis in several solid tumors [10]. In hematological cancers, less is known about the role of PRL-3. We have previously shown that $P R L-3$ is overexpressed in cancer cells from patient with multiple myeloma (MM), compared to normal plasma cells [11]. An oncogenic role of PRL-3 is described in acute myeloid leukemia (AML) [12-16] and chronic myeloid leukemia [17].

PRL-3 mRNA is highly expressed in BCR-ABL ALL [18], and was found overexpressed in ETV6-RUNX1 ALL, but did not impact cell viability [19]. Based on the oncogenic role and expression of PRL-3 in other hematological cancer, we aimed to explore PRL-3's role in the pathogenesis of B-ALL.

\section{RESULTS}

\section{PRL-3 was expressed in higher levels in B-ALL patient cells than in healthy control cells}

First, we investigated $P R L-3$ mRNA expression in 18 adult $\mathrm{B}-\mathrm{ALL}$ patient samples, peripheral mononuclear cells (PBMC) from two healthy controls and four B-ALL cell lines. Patient characteristics are shown in Supplementary Table 1. The expression level varied 600 -fold between samples (Figure 1A). There were no significant differences in overall survival, relapse, white blood cell count or percentage of blasts in peripheral blood between patients with expression of $P R L-3$ higher and lower than the median expression (data not shown). To assess PRL-3 protein expression, we measured PRL3 in BM from 12 children with B-ALL at the time of diagnosis using flow cytometry. Clinical data are shown in Supplementary Table 2. PRL-3 was significantly higher expressed in the leukemic B cells than in the individual patients' normal B cells ( $p<0,01)$ (Figure 1B). A search for "PTP4A3", "B cell ALL" and "Cancer Vs. Normal Analysis", in the open online gene expression profiling source www.oncomine.org, identified three datasets [2022]. $P R L-3$ expression was significantly higher in B-ALL samples than in normal samples in all three datasets (Figure 1C and Table 1). Two of the datasets [21, 22], provided ETV6-RUNX1 and BCR-ABL1 status. Dividing these data into positive or negative ETV6-RUNX1 (Figure 1D) or BCR-ABL1 (Figure 1E), resulted in higher PRL3 expression in the translocation positive group for both conditions. Collectively, this indicates that PRL-3 is overexpressed in B-ALL cells compared to normal B cells.

\section{PRL-3 was induced by cytokines in B-ALL cell lines}

To explore biological and molecular mechanism of PRL-3 in B-ALL, we chose to use the PreB-ALL cell lines Reh and MHH-CALL-4, which express moderate to high PRL-3 mRNA levels for further experiments (Figure 1A). PRL-3 protein expression is not always correlated with gene expression. We found PRL-3 protein present in Reh and MHH-CALL-4 cell lines as examined by intracellular flow cytometry (Figure 2A), by confocal microscopy (Figure 2B) and WB (Figure 2C). Because Reh cells expressed more PRL-3 protein than $\mathrm{MHH}-$ CALL-4, we focused subsequent experiments on Reh cells. Next, we examined whether PRL-3 could be induced by growth-inducing cytokines produced in the BM microenvironment. After 48 hours of stimulation with IL7 , there was an increase in protein expression in Reh, and to some extent in MHH-CALL-4 cells (Figure 2C). IL-7 induced a significant dose-dependent increase in $P R L-3$ mRNA in Reh (Figure 2D). Stimulation with IL-8, IGF-1 and SDF-1a increased $P R L-3$ expression significantly in Reh by $23 \%, 32 \%$ and $46 \%$ respectively (Figure $2 \mathrm{E}$ ).

\section{PRL-3 mediated migration and adhesion of B-ALL cell lines}

Previous studies have demonstrated a role for PRL-3 in the adhesion and migration of cancer cells. To examine PRL-3's effect on migration of leukemic B cells, we first knocked down PRL-3 in Reh cells using PRL3 shRNA (Supplementary Figure 1A). In a Transwell migration assay, addition of SDF-1a $(75 \mathrm{ng} / \mathrm{mL})$ to the lower compartment gave a good migratory response as expected (Figure 3A-3B). Knockdown of PRL-3 reduced SDF-1a-induced migration by 90 and $88 \%$ compared to control cells after 60 and 120 minutes, respectively (Figure 3A). To confirm these results, we wanted to see whether the small molecular compound, PRL-3 inhibitor I, could inhibit migration. The inhibitor $(40 \mu \mathrm{M})$ reduced the number of migrated cells in both Reh and MHH-CALL-4 cells, with $53 \%$ and $28 \%$, respectively (Figure 3B). The reduction in migration was not caused by anti-apoptotic effects of the PRL-3 inhibitor in Reh or MHH-CALL-4 as determined by annexin-V and PI (Supplementary Figure 2 ). These results indicate that PRL-3 mediated the SDF1a-induced migration of B-ALL cells.

Adhesion of leukemic cells to stroma is important for cell renewal and can promote drug resistance. To examine cell adhesion, we incubated Reh ShCTRL and Reh shPRL-3 cells in wells coated with fibronectin (FN) (Figure 3C). Stimulation with IL-7, IL-8 and IGF1 increased adhesion 2.5-3-fold in Reh shCTRL cells, 


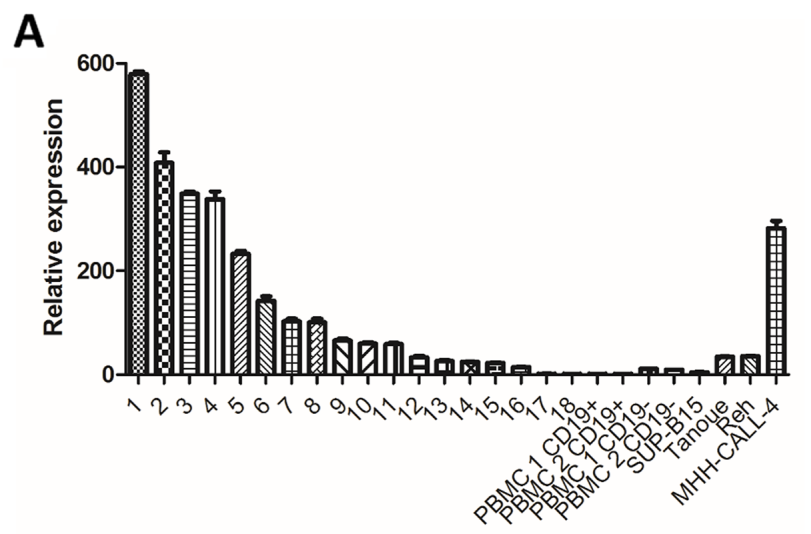

B

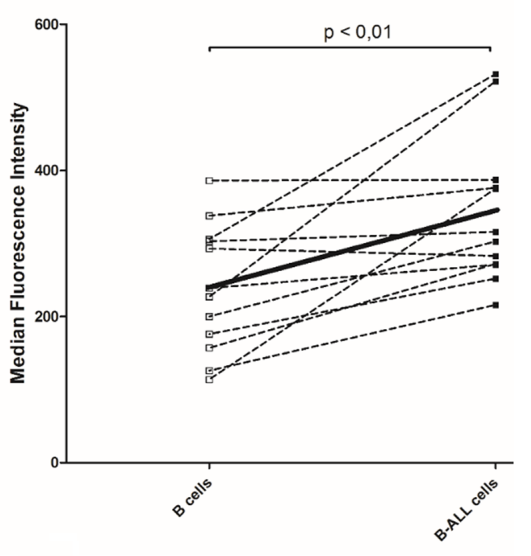

D

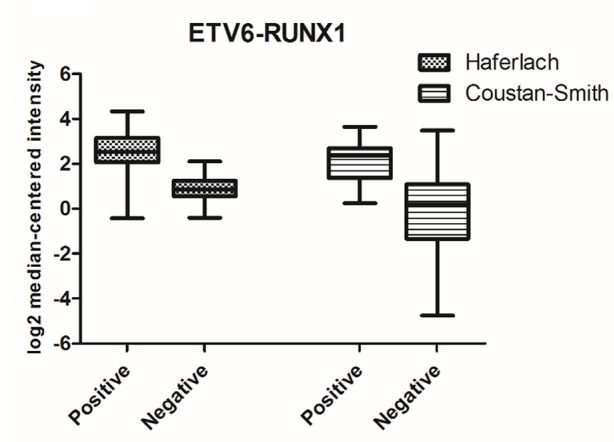

C

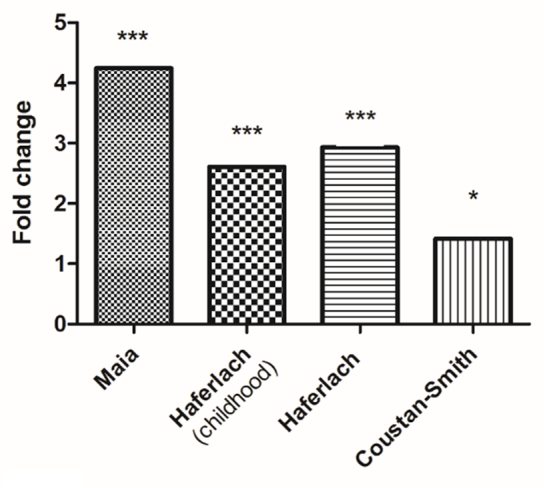

E

BCR-ABL1

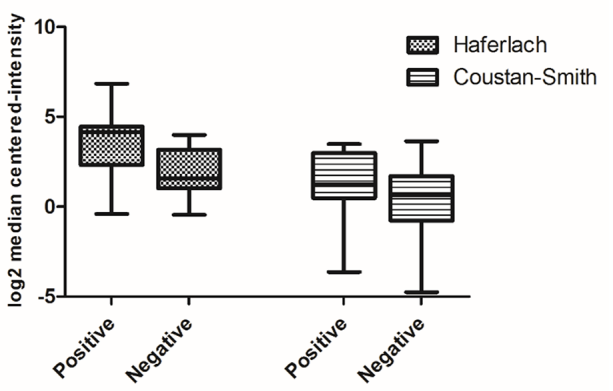

Figure 1: PRL-3 was expressed in higher levels in B-ALL patient cells than in healthy control cells. (A) Figure represents relative PRL-3 expression of 18 adult B-ALL patients, CD19+ and CD19-separated cells from 2 healthy controls and four cell lines.

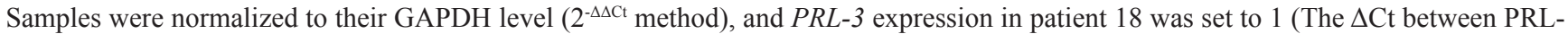
3 and GAPDH for patient 18 was $11,0( \pm 0,12))$. Error bars represents +1 SD of triplicates. Clinical data are shown in Supplementary Table 1. (B) In a consecutive examination of children with B-ALL, at the time of diagnosis, B-ALL cells expressed higher PRL-3 than normal B cells measured by flow cytometry. Values represent median fluorescence intensity (MFI) for each patient. The solid line indicates mean value for PRL-3 in normal and leukemic B cells. The mean value was significantly higher in B-ALL cells compared to normal cells $(\mathrm{p}<0.01)$. Clinical data are shown in Supplementary Table 2. (C) In three available datasets in the Oncomine database, $P R L-3$ was significantly overexpressed in B-ALL patients compared to normal control. Each bar represents fold change of $P R L-3$ in B-ALL samples compared to normal control. Further information of the datasets is shown in Table $1 .{ }^{*}$ indicates $p<0,05,{ }^{* * *}$ indicates $p<0,001$. Two of the datasets, Haferlach and Coustan-Smith, provided ETV6-RUNX1- and BCR-ABL1-status. Dividing the datasets in ETV6-RUNX1(D) and BCL-ABR1- (E) positive or negative, there was higher expression of $P R L-3$ in the positive group for both translocations. Still, translocation-negative samples expressed $P R L-3$. Line in the middle of the box represents median and boxes represents 25-75 percentiles of $\log 2$ median-centered intensity of $P R L-3$ expression. Whiskers represents minimum and maximum value. Normal samples and other leukemic samples are not shown. Data adapted from Oncomine. 
Table 1: Datasets obtained from www.oncomine.org

\begin{tabular}{lccccc}
\hline \multicolumn{1}{c}{ Datasets } & $\begin{array}{c}\text { B-ALL } \\
\text { samples }\end{array}$ & Control samples & Fold change & p-value & Reference \\
\hline Maia Leukemia (childhood) & 20 & $\begin{array}{c}7 \text { (Immature B-lymphocyte } \\
\text { and Pre B-Lymphocyte) }\end{array}$ & 4,24 & $2,45^{*} 10^{\wedge}-11$ & {$[20]$} \\
$\begin{array}{l}\text { Haferlach Leukemia } \\
\text { (childhood) }\end{array}$ & 359 & 74 (PBMC) & 2,61 & $2,18^{*} 10^{\wedge}-66$ & {$[21]$} \\
$\begin{array}{l}\text { Haferlach Leukemia } \\
\begin{array}{l}\text { Coustan-Smith Leukmia } \\
\text { (childhood) }\end{array}\end{array}$ & 147 & 74 (PBMC) & 2,93 & $2,72^{*} 10^{\wedge}-38$ & {$[21]$} \\
\hline
\end{tabular}

PBMC - Peripheral blood mononuclear cells.

whereas there was no increase in adhesion in Reh shPRL-3 cells (Figure 3C). These results indicate that PRL-3 is necessary for cytokine stimulated adhesion of leukemic cells to FN.

\section{Mechanism for PRL-3-induced migration and adhesion}

To elucidate possible mechanisms for the effects of PRL-3 on migration and adhesion, we looked into downstream targets of SDF-1a signaling involved in migration and adhesion including focal adhesion complex and $\mathrm{Ca}^{2+}$ mobilization.

\section{$\mathrm{Ca}^{2+}$ mobilization}

SDF-1a is known to induce a rapid $\mathrm{Ca}^{2+}$ flux in B-ALL cells, which can be measured using Fura Red. In the Reh shCTRL cells, there was a rapid increase in signal with a peak almost 4-fold above baseline after stimulation with SDF-1 $\alpha$, indicating an increase in $\mathrm{Ca}^{2+}$ flux. Knockdown of PRL-3 resulted in both slower response and lower amplitude of the $\mathrm{Ca}^{2+}$ signal, with the peak only 1,6-fold above baseline (Figure 4A). The percentage of responding cells was also lower in the PRL-3 knockdown cells (Figure 4A). Stimulation with the positive control, $\mathrm{CSK}$, induced the same $\mathrm{Ca}^{2+}$ flux in both cell lines (Figure 4B). Collectively, this indicates that PRL-3 amplifies the release of $\mathrm{Ca}^{2+}$ induced by the receptor for SDF-1a (CXCR4).

\section{Focal adhesion complex}

FAK and Src are key components in mediating migration and adhesion, and can be activated by SDF1a signaling. By Western blotting, we found that Reh shCTRL cells expressed more activated pFAK-Tyr576/577 than Reh knockdown cells (Figure 4C). Stimulation of Reh shCTRL cells with SDF-1a increased phosphorylation of FAK within 30 seconds, with a peak after 2.5 minutes. No such increase in FAK phosphorylation was seen in Reh PRL-3 knockdown cells (Figure 4C). The basal level of pSrcY-416 was higher in Reh control cells compared to Reh shPRL-3 cells, and did not increase with stimulation with SDF-1a (Figure 4C). Finally, we wanted to test whether the PRL-3-mediated effect of migration was caused by Src activation. Treating Reh shCTRL and Reh shPRL3 with two different Src inhibitors (SU6656 or PP2), before stimulation with SDF-1a in a transwell system, removed the PRL-3 effect on migration (Figure 4D).

The CXCR4 mRNA expression and surface expression, and surface expression of beta-1 integrin/ CD29 were unchanged following PRL-3 knockdown (data not shown). Taken together, this suggests that PRL-3 facilitates SDF-1a-induced $\mathrm{Ca}^{2+}$ mobilization and activation of FAK, and in the absence of SDF-1a, increases activation of FAK and Src.

\section{Drug resistance}

Finally, we screened for resistance to common anti-leukemic drugs caused by PRL-3. With cytarabine treatment, for 6 and 24 hours, we found that Reh shCTRL cells were significantly more viable compared to Reh shPRL-3 cells (Figure 5A-5B). We did not find any difference in viability after treatment with prednisone, daunorubicin or vincristine (data not shown).

\section{DISCUSSION}

In this study, we describe a possible role for PRL3 in the pathogenesis of B-ALL. We show that PRL-3 was expressed in B-ALL patient samples and cell lines. Further, we found that PRL-3 was overexpressed, at both mRNA and protein level, in B-ALL cells compared to healthy control cells. Importantly, via generation of PRL3 knockdown cells, we have shown that PRL-3 supports leukemic cell adhesion, migration and drug resistance. Collectively, this points to PRL-3 as a possible novel target in B-ALL.

We detected $P R L-3$ in most of our B-ALL samples, and in the Oncomine datasets $P R L-3$ was significantly higher expressed in B-ALL cells compared to normal control cells. ETV6-RUNX1- and BCR-ABL1-positive 


\section{A}

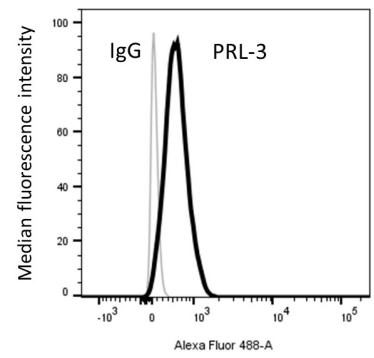

B

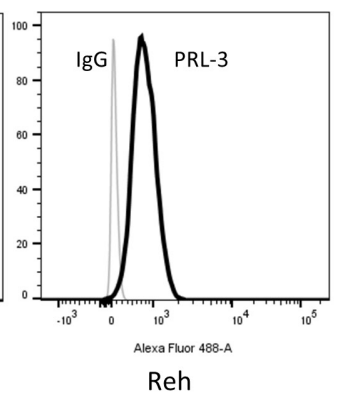

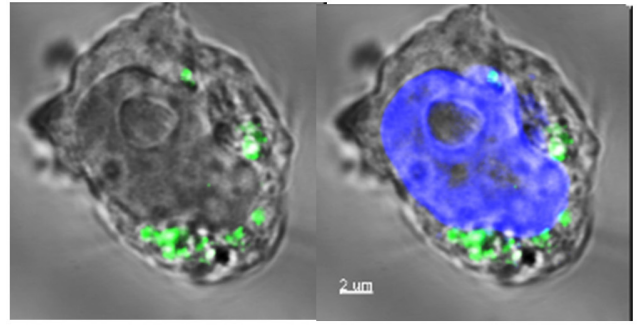

Reh

C

\begin{tabular}{|c|c|c|}
\hline IL7 $20 \mathrm{ng} / \mathrm{ml}$ & $\begin{array}{l}\text { Reh } \\
-\quad+\end{array}$ & $\begin{array}{r}\text { MHH-CALL-4 } \\
-\quad+\end{array}$ \\
\hline PRL-3 & 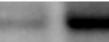 & 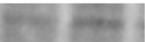 \\
\hline GAPDH & & $=1$ \\
\hline
\end{tabular}

E

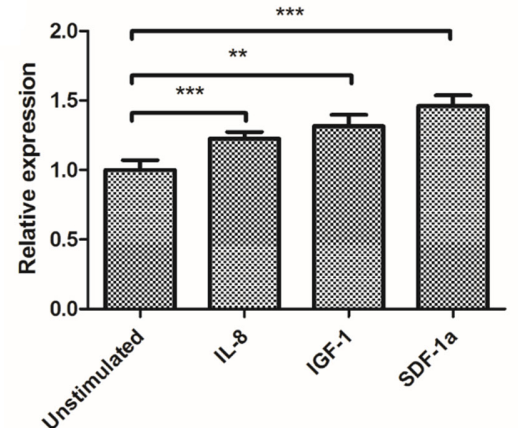

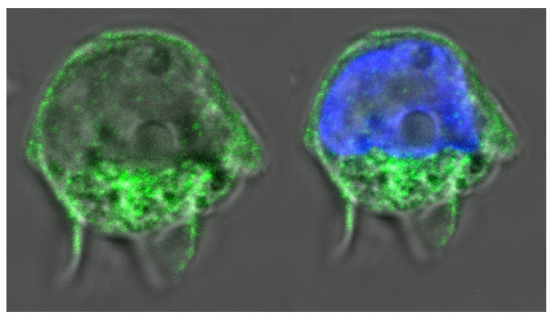

Reh-PRL-3

D

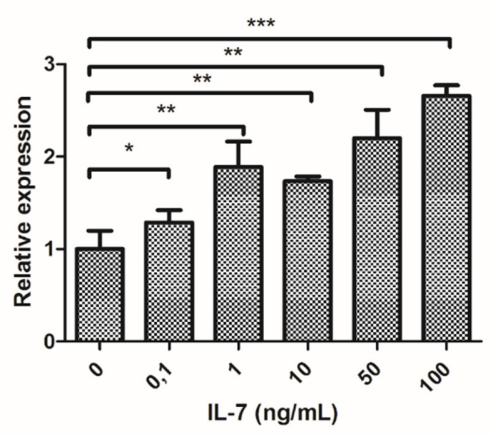

Figure 2: PRL-3 was induced by cytokines in B-ALL cell lines. (A) PRL-3 expression was detected by flow cytometry in Reh and MHH-CALL-4. Median fluorescence intensity value is normalized. (B) By confocal microscopy, PRL-3 was detected as punctuate structures in the cytoplasm of Reh cells. In Reh overexpressing PRL-3 cells, PRL-3 was also detected in the plasma membrane. Green is anti-PRL-3 and blue is DNA/nucleus. (C) PRL-3 protein was determined by Western analysis in Reh and MHH-CALL-4 cells stimulated by IL-7 $20 \mathrm{ng} / \mathrm{mL}$ for 48 hours. Stimulation with IL-7 increased PRL-3 protein in Reh cells. (D) IL-7 induced PRL-3 expression in a dosedependent manner.PRL-3 mRNA was quantified by qRT-PCR after Reh cells were stimulated by IL-7 for 48 hours. The relative expression level of $P R L-3$ in unstimulated cells was arbitrarily set to 1 , and samples were normalized to their GAPDH level (2- $2^{-\Delta C t}$ method). Error bars represents + 1 SD of triplicates. (E) IL-8, IGF-1 and SDF-1 $\alpha$ (all $100 \mathrm{ng} / \mathrm{mL}$ ) were able to induce mRNA expression of PRL-3. Error bars represents +1 SD of triplicates. ${ }^{*}$ indicates $\mathrm{p}<0,05 .{ }^{* *}$ indicates $\mathrm{p}<0,01 .{ }^{* * *}$ indicates $\mathrm{p}<0,001$. 
cases had a higher $P R L-3$ expression compared to negative samples, as also shown by others [18, 19]. Still, even translocation-negative samples expressed $P R L-3$. As shown by flow cytometry, leukemic cells had a significantly higher expression of PRL-3 compared to normal B cells from the same patient at the time of diagnosis. Overexpression of PRL-3 in B-ALL cells is in accordance with previous studies of PRL-3 expression in cancer tissues. In normal tissue, PRL-3 expression is generally low after the fetal period. PRL-3 mRNA can be found in heart and skeletal muscle, and at low levels in other tissues, but PRL-3 protein expression is rarely demonstrated $[10,23]$. In hematological cells, $P R L-3$ is expressed at low levels in megakaryocyte-erythroid progenitor cells, but not detected otherwise in bone marrow or in lymph nodes [23, 24]. PRL-3 has previously been reported to be expressed in hematological cancers like AML, MM [11-16], and based on our findings PRL-3 is also overexpressed in B-ALL.

We show that knockdown of PRL-3 with shRNA or inhibition of PRL-3 with PRL-3 inhibitor I reduced SDF$1 \alpha$-mediated migration, indicating a mechanistic role of PRL-3 in leukemic cell migration. Knockdown of PRL3 also reduced cytokine-stimulated adhesion of leukemic cells to FN. Motility and adhesion are important in the pathogenesis of cancer. SDF-1 $\alpha$ stimulates leukemic cells to migrate through stromal layers, enabling them to gain access to niches normally restricted to progenitor cells, and thereby favoring growth and survival [25]. Adhesion of leukemic cells within niches in the BM has been hypothesized to be a mechanism for relapse and drug resistance through CAM-DR $[5,6,26]$. Since the very first
A

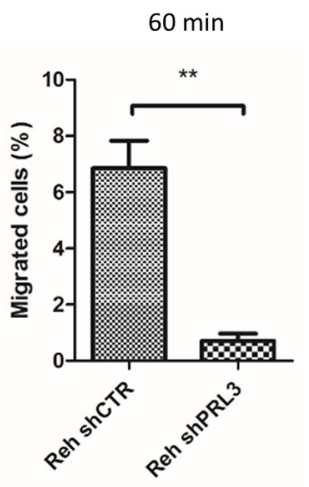

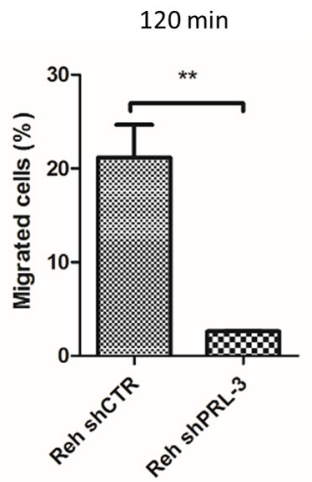

B
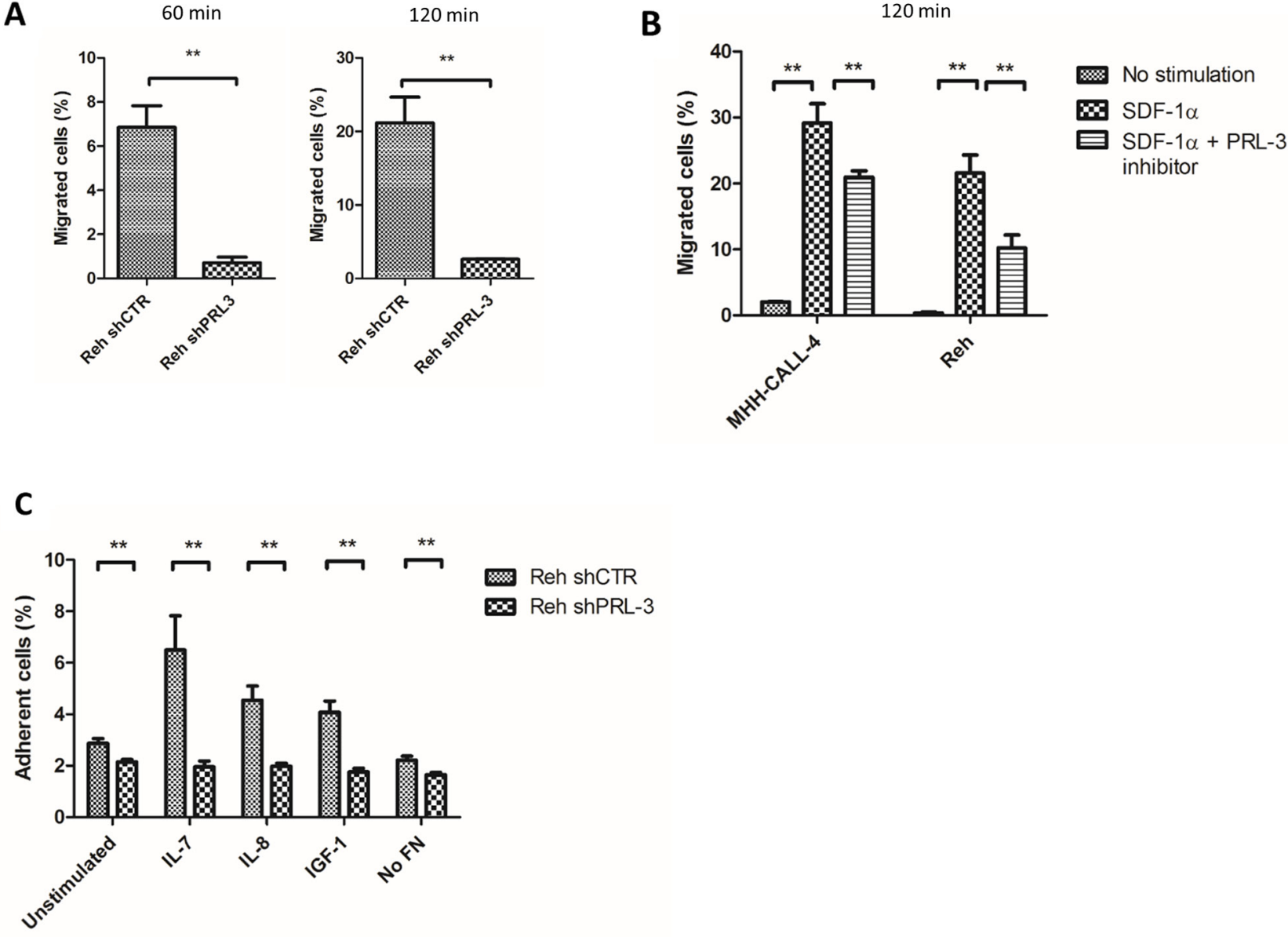

Figure 3: PRL-3 mediated migration and adhesion of B-ALL cell lines. (A) Knockdown of PRL-3 by shRNA in Reh cells reduced the migration towards a SDF-1a gradient by 90 and $88 \%$ after 60 (left) and 120 (right) minutes, respectively. Cells were seeded in the upper well of a transwell migration assay. SDF-1a $(75 \mathrm{ng} / \mathrm{mL})$ was added in the lower compartment. Cells that migrated to the lower compartment were counted. Bars represent the percentage of migrated cells from one representative of three independent experiments. Error bars represent $+1 \mathrm{SD}$ of three repeated counts in two parallels. (B) PRL-3 inhibitor I reduced SDF-1a mediated migration in Reh and MHH-CALL-4 with $53 \%$ and $28 \%$ respectively. Error bars represent +1 SD of three repeated counts in two parallels from one representative of three independent experiments. (C) Cytokine induced adhesion to FN is mediated by PRL-3. Reh shCTRL cells adhered significantly more to FN than Reh shPRL-3. Bars represents the percentage of adherent cells $(+1 \mathrm{SD})$ of six samples from one representative of three independent experiments. ${ }^{* *}$ indicates $\mathrm{p}<0,01 .{ }^{* * *}$ indicates $\mathrm{p}<0,001$. 
A
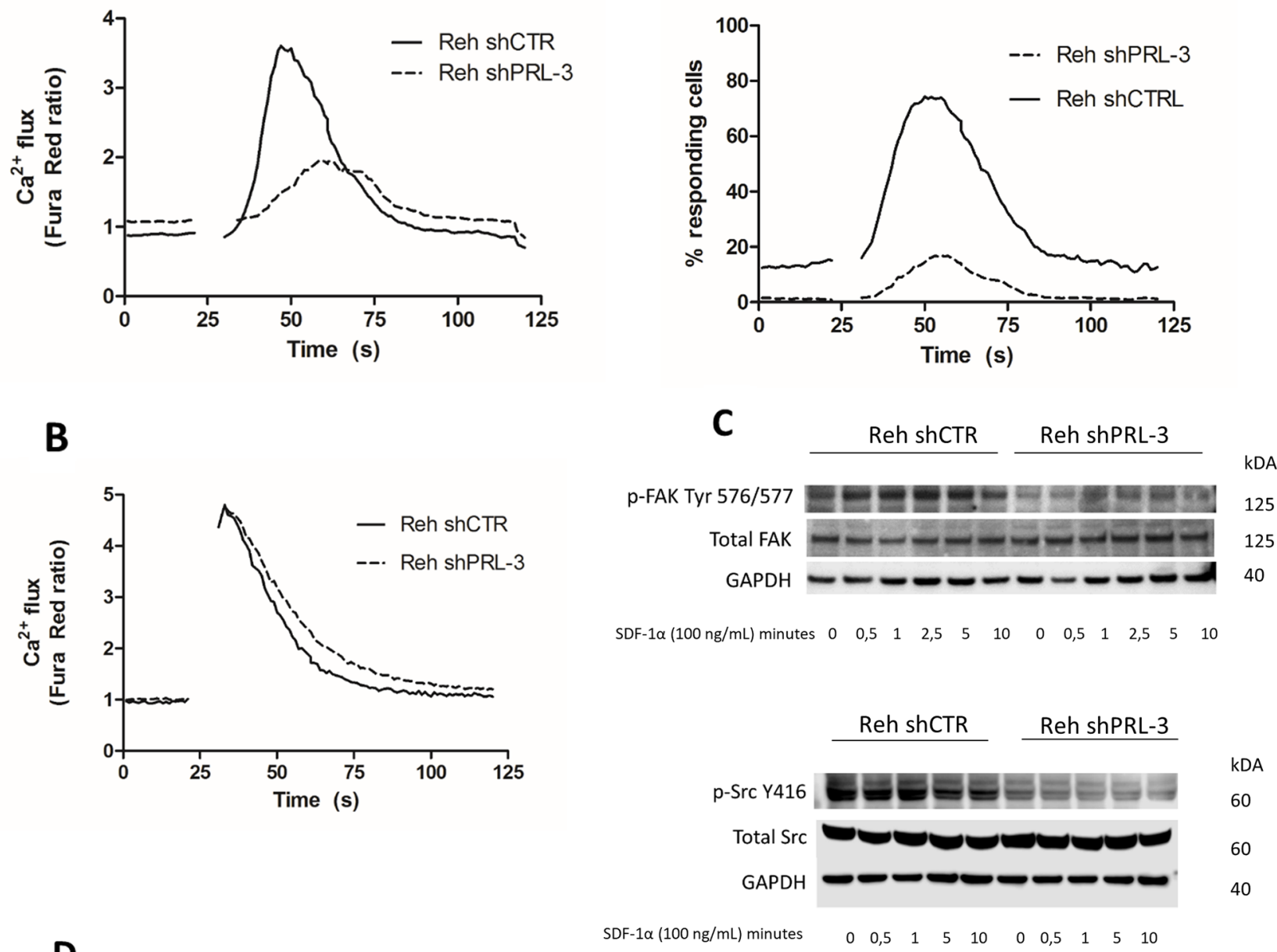

D

$\begin{array}{lllllllllll}\mathrm{SDF}-1 \alpha(100 \mathrm{ng} / \mathrm{mL}) \text { minutes } & 0 & 0,5 & 1 & 5 & 10 & 0 & 0,5 & 1 & 5 & 10\end{array}$

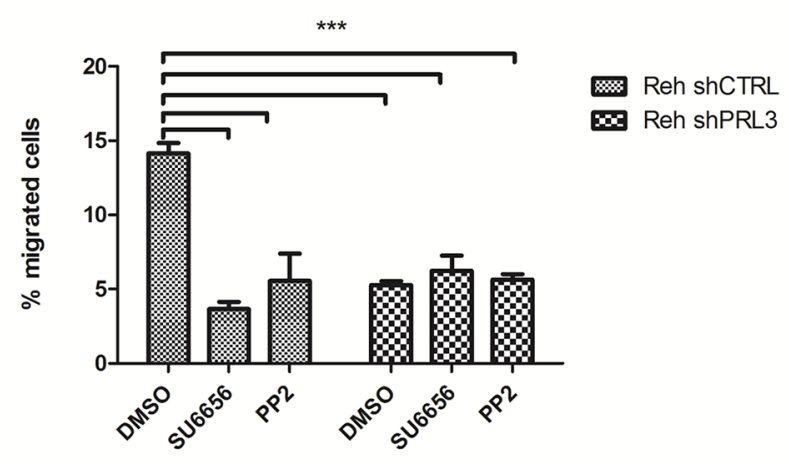

Figure 4: PRL-3 mediated calcium release, and increased pSrc-Y 416 and pFAK-Y576/577 as a possible mechanism for mediating migration and adhesion. (A) SDF-1 $\alpha$ stimulated release of calcium, and number of responding cells, was higher in the presence of PRL-3. (B) CSK stimulated calcium release was independent of PRL-3 expression. Gap indicates time used for removal of tube for adding stimulus. Background signal was recorded for 20 seconds, the sample was then removed and stimulated with SDF-1a (100 $\mathrm{ng} / \mathrm{mL}$ ) or CSK (1:500), and returned for continuing recording for total of 120 seconds. (C) SDF-1 $\alpha$ increased the phosphorylation of FAK Tyr 576/577 in Reh shCTRL. Phosphorylation of Src was also increased in Reh shCTRL compared to PRL-3 knockdown cells, but was not induced by SDF-1 $\alpha$ stimulation. Total Src and FAK was unchanged by PRL-3 knockdown. The membranes were reprobed for total Src or FAK, and GAPDH. (D) Src inhibition removed the PRL-3 effect of SDF-1a $(75 \mathrm{ng} / \mathrm{mL})$ induced migration. Bars represent the percentage of migrated cells from one representative of three independent experiments. Error bars represent $+1 \mathrm{SD}$ of three repeated counts in two parallels. ${ }^{* * *}$ indicates $\mathrm{p}<0,001$. 
paper on PRL-3, showing high expression of PRL-3 in liver metastases, but not in the primary colon tumor cells, there have been several reports describing a role for PRL-3 in migration and motility of cells [27]. In our experiments, knocking down PRL-3 was enough to almost completely abrogate migration, making PRL-3 an attractive target for novel therapies.

SDF-1 $\alpha$ signaling can activate FAK and Src, key components of focal adhesions complexes [28-30]. FAK integrates external signals to promote cell motility via different pathways involving Src, p130Cas, MAPK, guanine exchange factors (GEFs) and Rho-family GTPases [31]. Many of these are shown to be affected by PRL-3 [27]. Activation of FAK causes auto-phosphorylation at Tyr 397, which act as a binding site for Src, leading to phosphorylation of Tyr 576/577. Zimmerman et al found that absence of PRL-3 in endothelial cells, created from PRL-3-null mice, resulted in less phosphorylation of
Src and FAK [32]. We have recently shown that PRL-3 regulates Src activation in MM cells by increasing the phosphorylation of Src-Y416 [33], thus activating the oncogenic kinase. Similar to our present findings, Gari et al found that inhibition of PRL-3 by shRNA or an inhibitor (Ampi-109), inactivated Src by reducing the phosphorylation of Y416 in triple-negative breast cancer [34]. Blocking Src reduced the PRL-3-mediated effect on migration in our experiments. This, together with reduced Src activation in PRL-3 knockdown cells, indicates that Src activation is downstream of PRL-3. Taken together, our present study demonstrates that PRL-3 expression is necessary for SDF-1a induced migration B-ALL cells, presumably mediated through activation of Src and FAK.

The SDF-1 $\alpha$ receptor (CXR4) is a G proteincoupled receptor, and calcium flux is one of the first responses after ligand binding [35]. Calcium flux is used as a measure for activation of the CXCR4-receptor. SDF-
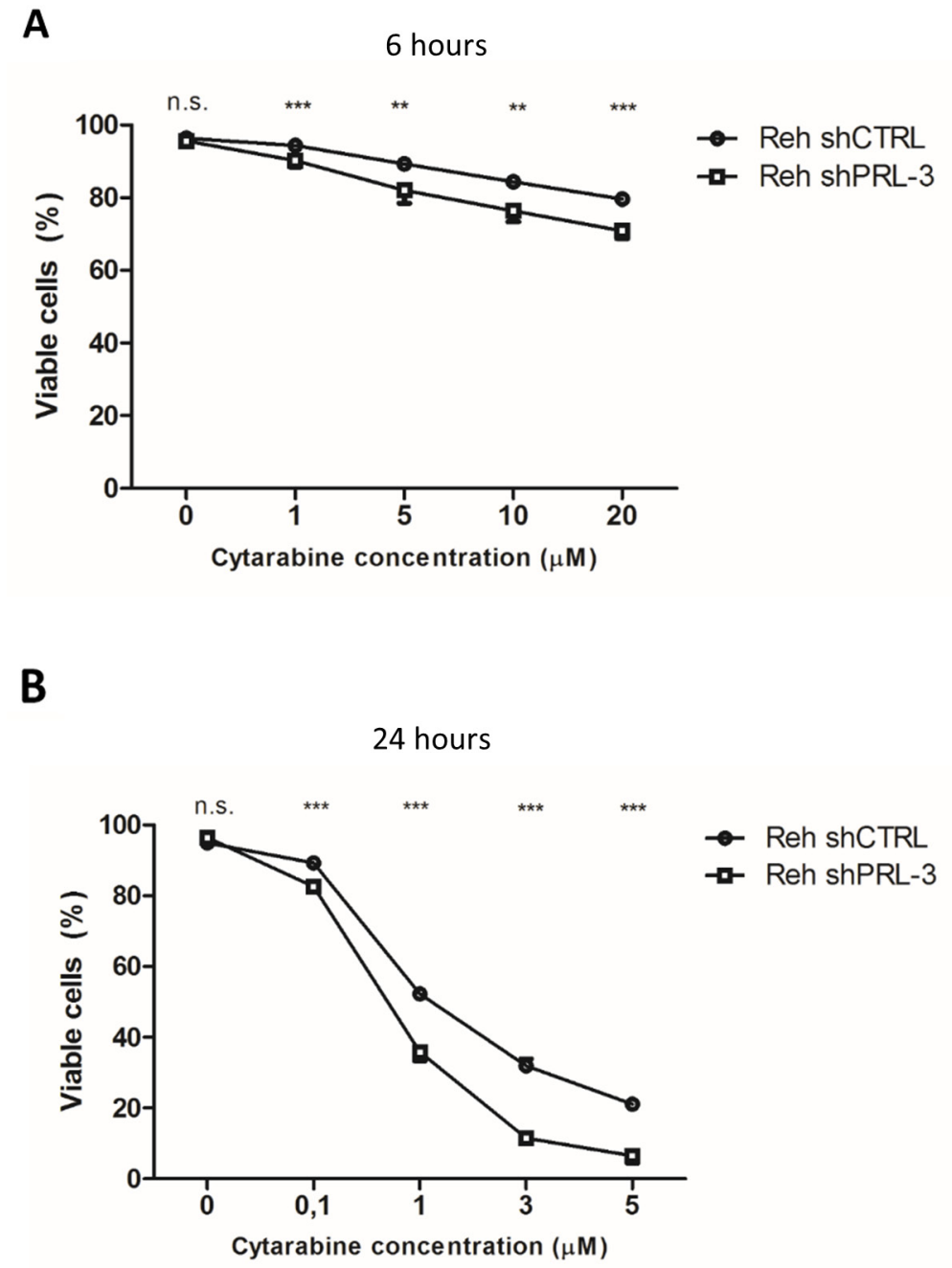

Figure 5: PRL-3 protects Reh cells from apoptosis induced by cytarabine after (A) 6 hours and (B) 24 hours. Error bars represent $+1 \mathrm{SD}$ of two independent experiments with duplicates. Viability was determined by annexin V-FITC/propidium iodide flow cytometry. ${ }^{* *}$ indicates $\mathrm{p}<0,01 .{ }^{* * *}$ indicates $\mathrm{p}<0,001$. 
$1 \alpha$ signaling further increase phosphorylation of focal adhesion components, including FAK [28]. Interestingly, we found that knockdown of PRL-3 impaired $\mathrm{Ca}^{2+}$ flux induced by CXCR4 activation, but not that induced by CSK. This indicates that PRL-3 is permissive for $\mathrm{Ca}^{2+}$ release by SDF-1 $\alpha$. The opposite was described in normal HEK293 cells, where overexpression of PRL-3 inhibited angiotensin-II stimulated $\mathrm{Ca}^{2+}$ flux [36]. Whether this is a cell-dependent, cancer- or cytokine-specific function of PRL-3 is unknown.

Drug resistance is a major cause of relapse of ALL. We show here that PRL-3 expression made Reh cells more resistant to cytarabine. Cytarabine is an antimetabolite prodrug. It is transported into cells through hENT1, and converted into active form, cytosine arabinoside triphosphate, by phosphorylation by deoxycytidine kinase (dCK) [37]. Whether PRL-3, as a phosphatase, is directly involved in inhibition the transportation, the conversion to the active form, or another mechanism, needs to be further explored. For the other drugs, we did not observe any difference in viability, which is in accordance with others [19].

\section{CONCLUSION}

We found that PRL-3 mRNA and protein was expressed in B-ALL patient samples and cell lines, and overexpressed in patient samples compared to normal controls. Knockdown of PRL-3 impeded both migration and adhesion of B-ALL cells in vitro, presumably through regulation of $\mathrm{Ca}^{2+}$ flux and phosphorylation of FAK and Src. Finally, PRL-3 expressing cells were more resistant to cytarabine treatment. This indicates that PRL-3 may represent a novel target for treatment of B-ALL.

\section{MATERIALS AND METHODS}

\section{Cell cultures and patient samples}

We used human B-ALL cell lines Reh (ATCC, Rockville, MD), MHH-CALL-4, Tanoue and SUP-B15 (DSMZ, Brauschweig, Germany). Cells were grown in RPMI-1640 supplemented with $2 \mathrm{mmol} / \mathrm{L}$ l-glutamine, $40 \mu \mathrm{g} / \mathrm{mL}$ gentamicin, and $10 \%$ (Reh and Tanoue) or $20 \%$ (MHH-CALL-4 and SUP-B15) heat-inactivated FCS (hereafter called medium). New cell cultures were seeded every 4 months from frozen vials aliquoted shortly after receiving the cells from the original supplier. Cells were cultured at $37^{\circ} \mathrm{C}$ in a humidified atmosphere with $5 \% \mathrm{CO}_{2}$, and growth medium were replenished twice weekly. Frozen isolated peripheral blood mononuclear cells (PBMC) from B-ALL patients were provided by The Regional Biobank of Central Norway and fresh BM samples were obtained from children admitted to St. Olavs hospital, both after obtaining informed consent. PBMC from healthy control were obtained from
Department of Immunology and Transfusion Medicine, St. Olavs hospital. PBMC were separated in CD19+ and CD19- cells using CD19 MicroBeads (Miltenyi Biotec $\mathrm{GmbH}$, Bergisch Gladbach, Germany) according to manufacturer's instructions.

\section{Antibodies, cytokines and other reagents}

Recombinant human IL-7, IL-8 and SDF-1 $\alpha$ were purchased from Peprotech (Rocky Hill, NJ), and insulinlike growth factor 1 (IGF-1) was from R\&D Systems (Abingdon, UK). Antibody against PRL-3 (318) (\#sc130355), Alexa 488-conjugated anti-PRL-3 (318) and control mouse $\mathrm{IgG}_{1}$-Alexa Fluor ${ }^{\circledR} 488$ (\#sc-3890) were bought from Santa Cruz Biotechnology (Santa Cruz, TX). Antibody against GAPDH was from Abcam (Cambridge, United Kingdom), and antibodies against phospho-focal adhesion kinase (pFAK) (Tyr576/577) (\#3281), total FAK (\#3285), pSrc (Y416) (\#2101) and total Src (\#2109) were from Cell Signaling Technology (Beverly, MA). PElabelled anti-human CD184 (C-X-C chemokine receptor type 4 (CXCR4)), PE-labelled anti-active human CD29 (HUTS-21) and irrelevant mouse $\mathrm{IgG}_{1}$ and $\mathrm{IgG}_{2}$ antibodies were from Pharmingen (Bedford, MA). Human plasma fibronectin (FN) was from BD Biosciences (Bedford, MA). PRL-3 inhibitor I (5-[[5-Bromo-2-[(2-bromophenyl) methoxy]phenyl]methylene]-2-thioxo-4-thiazolidinone),

SU6656 (2,3-Dihydro-N,N-dimethyl-2- oxo-3[(4,5,6,7-tetrahydro-1H-indol-2-yl)methylene $]-1 \mathrm{H}-$

indole- 5-sulfonamide), prednisolone, vincristine and daunorubicin were bought from Sigma-Aldrich (St. Louis, MO). PP2 Src inhibitor (4-Amino-3-(4-chlorophenyl)-1(t-butyl)-1H-pyrazolo[3,4-d] pyrimidine, 4-Amino-5-(4chlorophenyl)-7-(t-butyl)pyrazolo[3, 4-d] pyrimidine) was from Santa Cruz Biotechnology. The plasmids pLKO (non-silencing control) and shRNA-pLKO against PRL3 were a kind gift from Dr. Jim Lambert (University of Colorado, Denver, CO) [34].

\section{Lentiviral transduction for PRL-3 knockdown and overexpression}

For stable PRL-3 knockdown 293T packaging cells were transfected with individual pLKO-shRNA against PRL-3 or pLKO (control plasmid) in combination with psPAX2 (packaging plasmids) and pMD2.G (envelope plasmid) for virus production. Reh cells were transduced with viruses produced by packaging cells in order to establish Reh PRL-3 knockdown (Reh shPRL-3) and control cell line (Reh shCTRL). Knockdown was confirmed by qRT-PCR and intracellular flow cytometry (Supplementary Figure 1A-1B).

To establish cells with doxycycline $(1 \mu \mathrm{g} / \mathrm{mL})$ inducible PRL-3, 293T packaging cells were transfected with PCW57.1 (control plasmid) (AddGene, Cambridge, MA) and PRL3-PCW57.1 (plasmid containing the 
human PTP4A3 ORF cDNA) in combination with psPAX2 (packaging plasmids) and pMD2.G (envelope plasmid) for virus production. The PRL-3-PCW57.1 was made by performing an LR recombination reaction between the ORF PTP4A3 cDNA clone: ORFEXPRESS Gateway PLUS shuttle clone (GC-Z7908; GeneCopoeia, Rockville, USA) and the PCW57.1 plasmid. Reh cells were transduced with viruses produced by packaging cells in order to establish inducible overexpressing PRL3 (Reh-PRL-3) and empty control cell line (Reh-Mock). Transduced cells were selected in medium with puromycin $(0,5 \mu \mathrm{g} / \mathrm{mL})$.

\section{Immunoblotting}

Cells were treated as indicated, then pelleted, lysed and immunoblotted as previously described [38]. Images were acquired using LI-COR Odyssey Fc and analyzed with Image Studio Software (LI-COR, Lincoln, Nebraska). All experiments were conducted at least three times.

\section{RNA isolation, cDNA synthesis and quantitative real time PCR (qRT-PCR)}

Isolation of RNA and cDNA synthesis were performed as previously described [39]. For relative quantification, we used the comparative $2^{\text {-DDCT }}$-method, with GAPDH as endogenous reference. All samples were run in triplicate. The following primers were used: PTP4A3 (Hs02341135_m1), CXCR4 (Hs00607978_s1) and GAPDH (Hs99999905_m1) (TaqMan). Analysis was performed using Step One Software 2.3 (Applied Biosystems).

\section{Apoptosis assay}

Viability and apoptosis were evaluated using Annexin V-FITC binding and propidium iodide (PI) uptake (APOPTEST-FITC kit; Nexins Research, Kattendijke, The Netherlands). Briefly, cells were washed once with icecold PBS, resuspended and incubated on ice for 1 hour in the dark in $300 \mu \mathrm{L}$ binding buffer with $0,25 \mu \mathrm{L}$ annexin V-FITC. PI was added 5 minutes before the samples were analyzed by flow cytometry using BD LSRII Flow Cytometer (BD Biosciences, Franklin Lakes, NJ). All conditions were run in duplicate and repeated three times.

\section{Migration assay}

Cells $\left(4^{*} 10^{5}\right)$ were seeded into the upper chamber of a Transwell culture plate (polycarbonate membrane with pore size $3 \mu \mathrm{m}$, Corning, NY). In experiments using inhibitors, cells were pre-treated with or without PRL-3 inhibitor I $(40 \mu \mathrm{M})$ for 30 minutes, SU6656 $(5 \mu \mathrm{M})$ or PP2 $(10 \mu \mathrm{M})$ for 4 hours before seeded into the upper chamber. The lower chamber was loaded with $600 \mu \mathrm{L}$ medium with
SDF-1 $\alpha(75 \mathrm{ng} / \mathrm{mL})$ as a chemoattractant, and PRL-3 inhibitor I $(40 \mu \mathrm{M})$, SU6656 $(5 \mu \mathrm{M})$ or PP2 $(10 \mu \mathrm{M})$ as indicated. The cells that migrated through the membrane to the lower chamber were counted using Coulter Counter Z1 (Bechman Coulter, Fullerton, CA). All conditions were performed in duplicate, and all experiments were performed three times.

\section{Adhesion assay}

96-well round-bottomed plates were coated with human FN $(20 \mu \mathrm{g} / \mathrm{mL})$ overnight at $4{ }^{\circ} \mathrm{C}$, washed three times with PBS and blocked with $0,1 \%$ BSAPBS for 1 hour at room temperature, and then washed three times with Hanks' Balanced Salt Solution (HBSS) (Sigma-Aldrich). Cells were labelled with acetoxymethyl ester-2',7' bis-(2-carboxyethyl)-5-(and-6)carboxyfluorescein (BCECF-AM) (Sigma-Aldrich), for 1 hour in room temperature, and washed three times with HBSS before stimulated with cytokines as indicated for 60 minutes $\left(5^{*} 10^{4}\right.$ cells/well). Non-adherent cells were washed away by carefully pipetting with HBSS. Adherent cells were lysed with $1 \%$ Triton-X. Fluorescence level at $538 \mathrm{~nm}$ was read by Victor ${ }^{3}$ plate reader and Wallac 1420 Work Station software. Adherent cells were calculated as percent of signal before washing. All conditions were performed in six parallel readings, and each experiment was performed three times.

\section{Flow cytometry}

For intracellular flow cytometry, cells $\left(1^{*} 10^{6}\right)$ were fixed and permeabilized (Fix \& Perm ${ }^{\circledR C}$ Cell Fixation \& Cell Permeabilization Kit) (ThermoFisher Scientific, Waltham, MA) according to manufacturer's instructions. Cells were then incubated with antibody for 20 minutes in room temperature, and then washed and resuspended in $0,1 \%$ BSA-PBS. For surface proteins, cells $\left(1^{*} 10^{6}\right)$ were incubated with primary antibody and secondary antibody on ice. Flow cytometry was performed with BD LSRII Flow Cytometer.

\section{Calcium flux}

The method for measuring $\mathrm{Ca}^{2+}$ flux was adopted from $[40,41]$. Cells $\left(1^{*} 10^{6}\right)$ were washed in PBS (calcium-free), stained with $1 \mu \mathrm{M}$ Fura Red-AM (Invitrogen) for $30 \mathrm{~min}$ at $37^{\circ} \mathrm{C}$, washed again and resuspended in PBS. Emission was obtained with Qdot-700 and PE-Cy5-5 filter. Background signal was recorded for 20 seconds before the tube was removed and SDF-1 $\alpha(100 \mathrm{ng} / \mathrm{mL})$ or Cell Stimulation Cocktail (CSK) (500X) (eBioscience, San Diego, CA) 1:500 was added. Data, including the ratiometric Fura Red Ratio between Qdot-700 and PE-Cy5-5 and the percentage of responding cells, were analyzed with FlowJo v. 10.1.5 (FlowJo, LLC, Ashland, OR). 


\section{Confocal microscopy}

Cells were allowed to adhere to Poly-L-lysine $(0,01$ $\%$ ), and then fixed with $4 \%$ paraformaldehyde before permeabilized with PBS, $5 \%$ human serum and 0,5\% saponin. PRL-3 was detected with directly conjugated PRL-3-Alexa 488 antibody and the nucleus was stained with Hoechst 33342 (ThermoFisher). Confocal imaging was performed using the Leica SP8 STED 3D microscope (Wetzlar, Germany). Imaris (Bitplane, Zurich, Switzerland) was used for imaging editing.

\section{Statistics}

Statistical significance was determined using Student's $t$-test in IBM SPSS Statistics ver. 24 .

\section{Ethics}

The use and storage of patient samples was approved by the Regional Ethics Committee (Approval \#28/99 and 2015/700-03), and all patients gave informed consent.

\section{Author contributions}

MAH, MB, TBR designed the study. MAH, PA, ENV, MHF, BL performed experiments and acquired data. MAH, PA, ENV, TSS, MB, TBR analyzed and interpreted the data. MAH, PA, ENV, MHF, BL, TSS, MB, TBR write and/or reviewed the manuscript.

\section{ACKNOWLEDGMENTS}

The authors would like to thank Hanne Hella, Berit Størdal, Lill Anny Gunnes Grøseth and Solveig Kvam for technical support.

\section{CONFLICTS OF INTEREST}

The authors declare no conflicts of interest.

\section{FUNDING}

This work was financially supported by Joint Research Committee between St. Olavs Hospital HF and Faculty of Medicine and Health Science, NTNU.

\section{REFERENCES}

1. Hunger SP, Mullighan CG. Acute Lymphoblastic Leukemia in Children. N Engl J Med. 2015; 373: 1541-52. https://doi. org/10.1056/NEJMra1400972.

2. Pui CH, Carroll WL, Meshinchi S, Arceci RJ. Biology, risk stratification, and therapy of pediatric acute leukemias: an update. J Clin Oncol. 2011; 29: 551-65. https://doi. org/10.1200/JCO.2010.30.7405.
3. Manabe A, Coustan-Smith E, Behm FG, Raimondi SC, Campana D. Bone marrow-derived stromal cells prevent apoptotic cell death in B-lineage acute lymphoblastic leukemia. Blood. 1992; 79: 2370-7.

4. Makrynikola V, Bradstock KF. Adhesion of precursor-B acute lymphoblastic leukaemia cells to bone marrow stromal proteins. Leukemia. 1993; 7: 86-92.

5. Hsieh YT, Gang EJ, Geng H, Park E, Huantes S, Chudziak D, Dauber K, Schaefer P, Scharman C, Shimada H, Shojaee $\mathrm{S}$, Klemm L, Parameswaran R, et al. Integrin alpha4 blockade sensitizes drug resistant pre-B acute lymphoblastic leukemia to chemotherapy. Blood. 2013; 121: 1814-8. https://doi.org/10.1182/blood-2012-01-406272.

6. Shishido S, Bönig H, Kim YM. Role of integrin alpha4 in drug resistance of leukemia. Front Oncol. 2014; 4: 99. https://doi.org/10.3389/fonc.2014.00099.

7. van der Plas DC, Smiers F, Pouwels K, Hoefsloot LH, Lowenberg B, Touw IP. Interleukin-7 signaling in human B cell precursor acute lymphoblastic leukemia cells and murine BAF3 cells involves activation of STAT1 and STAT5 mediated via the interleukin-7 receptor alpha chain. Leukemia. 1996; 10: 1317-25.

8. Bradstock KF, Makrynikola V, Bianchi A, Shen W, Hewson J, Gottlieb DJ. Effects of the chemokine stromal cell-derived factor- 1 on the migration and localization of precursor-B acute lymphoblastic leukemia cells within bone marrow stromal layers. Leukemia. 2000; 14: 882-8. https://doi.org/10.1038/sj.leu.2401729.

9. Saha S, Bardelli A, Buckhaults P, Velculescu VE, Rago C, St Croix B, Romans KE, Choti MA, Lengauer C, Kinzler KW, Vogelstein B. A phosphatase associated with metastasis of colorectal cancer. Science. 2001; 294: 1343-6. https:// doi.org/10.1126/science.1065817.

10. Al-Aidaroos AQ, Zeng Q. PRL-3 phosphatase and cancer metastasis. J Cell Biochem. 2010; 111: 1087-98. https://doi. org/10.1002/jcb.22913.

11. Fagerli UM, Holt RU, Holien T, Vaatsveen TK, Zhan F, Egeberg KW, Barlogie B, Waage A, Aarset H, Dai HY, Shaughnessy JD, Sundan A, Borset M. Overexpression and involvement in migration by the metastasis-associated phosphatase PRL-3 in human myeloma cells. Blood. 2008; 111: 806-15. https://doi.org/10.1182/blood-2007-07-101139.

12. Zhou J, Chong PS, Lu X, Cheong LL, Bi C, Liu SC, Zhou Y, Tan TZ, Yang H, Chung TH, Zeng Q, Chng WJ. Phosphatase of regenerating liver-3 is regulated by signal transducer and activator of transcription 3 in acute myeloid leukemia. Exp Hematol. 2014; 42: 1041-1052.e2. https:// doi.org/10.1016/j.exphem.2014.08.001.

13. Chong PS, Zhou J, Cheong LL, Liu SC, Qian J, Guo T, Sze SK, Zeng Q, Chng WJ. LEO1 is regulated by PRL-3 and mediates its oncogenic properties in acute myelogenous leukemia. Cancer Res. 2014; 74: 3043-53. https://doi. org/10.1158/0008-5472.CAN-13-2321.

14. Park JE, Yuen HF, Zhou JB, Al-Aidaroos AQ, Guo K, Valk PJ, Zhang SD, Chng WJ, Hong CW, Mills K, Zeng 
Q. Oncogenic roles of PRL-3 in FLT3-ITD induced acute myeloid leukaemia. EMBO Mol Med. 2013; 5: 1351-66. https://doi.org/10.1002/emmm.201202183.

15. Zhou J, Bi C, Chng WJ, Cheong LL, Liu SC, Mahara S, Tay KG, Zeng Q, Li J, Guo K, Tan CP, Yu H, Albert DH, et al. PRL-3, a metastasis associated tyrosine phosphatase, is involved in FLT3-ITD signaling and implicated in antiaml therapy. PLoS One. 2011; 6: e19798. https://doi. org/10.1371/journal.pone.0019798.

16. Qu S, Liu B, Guo X, Shi H, Zhou M, Li L, Yang S, Tong $\mathrm{X}$, Wang $\mathrm{H}$. Independent oncogenic and therapeutic significance of phosphatase PRL-3 in FLT3-ITD-negative acute myeloid leukemia. Cancer. 2014; 120: 2130-41. https://doi.org/10.1002/cncr.28668.

17. Zhou J, Cheong LL, Liu SC, Chong PS, Mahara S, Bi C, Ong KO, Zeng Q, Chng WJ. The pro-metastasis tyrosine phosphatase, PRL-3 (PTP4A3), is a novel mediator of oncogenic function of BCR-ABL in human chronic myeloid leukemia. Mol Cancer. 2012; 11: 72. https://doi. org/10.1186/1476-4598-11-72.

18. Juric D, Lacayo NJ, Ramsey MC, Racevskis J, Wiernik PH, Rowe JM, Goldstone AH, O'Dwyer PJ, Paietta E, Sikic BI. Differential gene expression patterns and interaction networks in BCR-ABL-positive and -negative adult acute lymphoblastic leukemias. J Clin Oncol. 2007; 25: 1341-9. https://doi.org/10.1200/JCO.2006.09.3534.

19. Grönroos T, Teppo S, Mehtonen J, Laukkanen S, Liuksiala T, Nykter M, Heinäniemi M, Lohi O. Overexpression of PTP4A3 in ETV6-RUNX1 acute lymphoblastic leukemia. Leuk Res. 2017; 54: 1-6. https://doi.org/10.1016/j. leukres.2016.12.005.

20. Maia S, Haining WN, Ansén S, Xia Z, Armstrong SA, Seth NP, Ghia P, den Boer ML, Pieters R, Sallan SE, Nadler LM, Cardoso AA. Gene expression profiling identifies $\mathrm{BAX}-\delta$ as a novel tumor antigen in acute lymphoblastic leukemia. Cancer Res. 2005; 65: 10050-8. https://doi. org/10.1158/0008-5472.CAN-05-1574.

21. Haferlach T, Kohlmann A, Wieczorek L, Basso G, Te Kronnie G, Béné MC, De Vos J, Hernández JM, Hofmann WK, Mills KI, Gilkes A, Chiaretti S, Shurtleff SA, et al. Clinical utility of microarray-based gene expression profiling in the diagnosis and subclassification of leukemia: report from the international microarray innovations in leukemia study group. J Clin Oncol. 2010; 28: 2529-37. https://doi.org/10.1200/JCO.2009.23.4732.

22. Coustan-Smith E, Song G, Clark C, Key L, Liu P, Mehrpooya M, Stow P, Su X, Shurtleff S, Pui CH, Downing JR, Campana D. New markers for minimal residual disease detection in acute lymphoblastic leukemia. Blood. 2011; 117: 6267-76. https://doi.org/10.1182/ blood-2010-12-324004.

23. Uhlen M, Fagerberg L, Hallstrom BM, Lindskog C, Oksvold P, Mardinoglu A, Sivertsson A, Kampf C, Sjostedt E, Asplund A, Olsson I, Edlund K, Lundberg E, et al. Tissue-based map of the human proteome. Science 2015; 347: 1260419-1260419. https://doi.org/10.1126/ science. 1260419.

24. Kobayashi M, Chen S, Gao R, Bai Y, Zhang ZY, Liu Y. Phosphatase of regenerating liver in hematopoietic stem cells and hematological malignancies. Cell Cycle. 2014; 13 : 2827-35. https://doi.org/10.4161/15384101.2014.954448.

25. Burger JA, Bürkle A. The CXCR4 chemokine receptor in acute and chronic leukaemia: a marrow homing receptor and potential therapeutic target. Br J Haematol. 2007; 137: 288-96. https://doi.org/10.1111/j.1365-2141.2007.06590.x.

26. Pillozzi S, Masselli M, De Lorenzo E, Accordi B, Cilia E, Crociani O, Amedei A, Veltroni M, D’Amico M, Basso G, Becchetti A, Campana D, Arcangeli A. Chemotherapy resistance in acute lymphoblastic leukemia requires hERG1 channels and is overcome by hERG1 blockers. Blood. 2011; 117: 902-14. https://doi.org/10.1182/ blood-2010-01-262691.

27. Bessette DC, Qiu D, Pallen CJ. PRL PTPs: mediators and markers of cancer progression. Cancer Metastasis Rev. 2008; 27: 231-52. https://doi.org/10.1007/ s10555-008-9121-3.

28. Wang JF, Park IW, Groopman JE. Stromal cell-derived factor-1alpha stimulates tyrosine phosphorylation of multiple focal adhesion proteins and induces migration of hematopoietic progenitor cells: roles of phosphoinositide-3 kinase and protein kinase C. Blood. 2000; 95: 2505-13.

29. Glodek AM, Le Y, Dykxhoorn DM, Park SY, Mostoslavsky G, Mulligan R, Lieberman J, Beggs HE, Honczarenko $M$, Silberstein LE. Focal adhesion kinase is required for CXCL12-induced chemotactic and pro-adhesive responses in hematopoietic precursor cells. Leukemia. 2007; 21: 1723-32. https://doi.org/10.1038/sj.leu.2404769.

30. Teicher BA, Fricker SP. CXCL12 (SDF-1)/CXCR4 pathway in cancer. Clinical Cancer Research. 2010; 16: 2927-31. https://doi.org/10.1158/1078-0432.CCR-09-2329.

31. Huveneers S, Danen EH. Adhesion signaling - crosstalk between integrins, Src and Rho. J Cell Sci. 2009; 122: 1059-69. https:// doi.org/10.1242/jcs.039446.

32. Zimmerman MW, McQueeney KE, Isenberg JS, Pitt BR, Wasserloos KA, Homanics GE, Lazo JS. Protein-tyrosine phosphatase 4A3 (PTP4A3) promotes vascular endothelial growth factor signaling and enables endothelial cell motility. J Biol Chem. 2014; 289: 5904-13. https://doi. org/10.1074/jbc.M113.480038.

33. Abdollahi P, Vandsemb EN, Hjort MA, Misund K, Holien T, Sponaas AM, Rø TB, Slørdahl TS, Børset M. Src family kinases are regulated in multiple myeloma cells by phosphatase of regenerating liver-3. Mol Cancer Res. 2017; 15: 69-77. https://doi.org/10.1158/1541-7786.MCR-16-0212.

34. Gari HH, DeGala GD, Ray R, Lucia MS, Lambert JR. PRL-3 engages the focal adhesion pathway in triplenegative breast cancer cells to alter actin structure and substrate adhesion properties critical for cell migration 
and invasion. Cancer Lett. 2016; 380: 505-12. https://doi. org/10.1016/j.canlet.2016.07.017.

35. Burger JA, Burger M, Kipps TJ. Chronic lymphocytic leukemia B cells express functional CXCR4 chemokine receptors that mediate spontaneous migration beneath bone marrow stromal cells. Blood. 1999; 94: 3658-67.

36. Matter WF, Estridge T, Zhang C, Belagaje R, Stancato L, Dixon J, Johnson B, Bloem L, Pickard T, Donaghue M, Acton S, Jeyaseelan R, Kadambi V, et al. Role of PRL3, a human muscle-specific tyrosine phosphatase, in angiotensin-II signaling. Biochem Biophys Res Commun. 2001; 283: 1061-8. https://doi.org/10.1006/bbrc.2001.4881.

37. Galmarini CM, Mackey JR, Dumontet C. Nucleoside analogues: mechanisms of drug resistance and reversal strategies. Leukemia. 2001; 15: 875-90. https://doi. org/10.1038/sj.leu.2402114.

38. Slørdahl TS, Denayer T, Moen SH, Standal T, Børset M, Ververken C, Rø TB. Anti-c-MET Nanobody ${ }^{\circledR}$ - a new potential drug in multiple myeloma treatment. Eur J Haematol. 2013; 91: 399-410. https://doi.org/10.1111/ ejh.12185.

39. Slørdahl TS, Abdollahi P, Vandsemb EN, Rampa C, Misund K, Baranowska KA, Westhrin M, Waage A, Rø TB, Børset $\mathrm{M}$. The phosphatase of regenerating liver-3 (PRL-3) is important for IL-6-mediated survival of myeloma cells. Oncotarget. 2016; 7: 27295-306. https://doi.org/10.18632/ oncotarget.8422.

40. Vines A, McBean GJ, Blanco-Fernández A. A flowcytometric method for continuous measurement of intracellular Ca2+ concentration. Cytom Part A. 2010; 77 : 1091-7. https://doi.org/10.1002/cyto.a.20974.

41. Wendt ER, Ferry H, Greaves DR, Keshav S. Ratiometric analysis of fura red by flow cytometry: a technique for monitoring intracellular calcium flux in primary cell subsets. PLoS One. 2015; 10: 1-13. https://doi.org/10.1371/ journal.pone.0119532. 